\title{
Palavras-imagens, escrita biográfica e os fantasmas de Derrida
}

\author{
Andreia A. Marin (UFTM)* \\ https://orcid.org/0000-0001-8599-0506
}

\section{Resumo:}

O impulso da presente escrita foi um olhar de Derrida, que parecia ver sem ser visto, em D'ailleurs Derrida. As palavras-imagens de alguém que já morreu, portanto, de seus espectros, motivam as inquietações que norteiam o texto. São discutidos os conceitos de fonocentrismo, mal de arquivo e espectralidade, a partir das obras Gramatologia, Mal de Arquivo e Espectros de Marx, com o objetivo de pensar até que ponto a escrita, em especial a escrita biográfica, é permissiva aos espectros ou possibilita seu apagamento. Ao final, enfatiza-se a questão sobre a intenção do autor que escreve, de garantir a permanência de sua própria existência ou de apontar incansavelmente para o que permanece refratário à síntese analítica e histórica e à tendência ao arquivamento.

Palavras-chave: Espectros. Mal de Arquivo. Fonocentrismo. Escrita.

\section{Abstract:}

\section{Image-words, biographical writing and the ghosts of Derrida}

The impulse of this writing was a look of Derrida, who seemed to see without being seen, in D'ailleurs Derrida. The words-images of someone who has died, of their spectra, motivate the concerns that guide the text. The concepts of phonocentrism, archival and spectrality are discussed, based on the works Of Grammatology, Archive Fever and Specters of Marx. The objective is to think to what extent writing, especially biographical writing, is permissive to the spectra or makes it possible to erase them. In the end, the question about the intention of the author who writes is emphasized: whether he intends to guarantee the permanence of his own existence or to point tirelessly to what remains refractory to the analytical and historical synthesis and the tendency to archive.

Keywords: Specters. Archive Fever. Phonocentrism. Writing.

* Docente no Instituto de Educação, Letras, Artes e Ciências Humanas e Sociais da Universidade Federal do Triângulo Mineiro - UFTM. E-mail: aamarinea@gmail.com. 


\section{Introdução}

Antes de qualquer impulso de escrita, me pergunto, diante de um aceno de Jacques Derrida, se se trata de conduzir a força de sua presença não presente a um esboço, uma materialização linguageira e se, ao fazê-lo, não estaria cometendo o risco de uma redução, uma busca de sentidos marcada por alguma intenção arquivística, uma conjuração de fantasmas.

Já estaria bastante influenciada pelas leituras de Derrida para, diante de seu rosto na tela, ousar nomear e reduzir fantasmagorias, mas também esquivar-me delas, de maneira que assumo os riscos e me lanço a escrever sobre fantasmas. Não o fantasma de Marx, mas o de quem pressentiu que, na fantasmagoria, não há vazio. É o mesmo Derrida que me interpela na tela e que parece me olhar de algum canto para além dela, vendo-me sem ser totalmente visto.

$\mathrm{Na}$ tela, ao fim de uma jornada de 1h07'57', na pausa dada em 1h06'57' de D'ailleurs Derrida (FATHY, 1999) ${ }^{1}$, me dou conta de estar diante de um fantasma. 0 rosto que aparece na tela é de alguém que já morreu, mas esse olhar que aparece focado está tão presente no silêncio em que imerge que parece impossível tomá-lo como pura ausência. De tudo que foi dito no tempo do filme, parece sempre haver um algo mais a encontrar. Mas, não nos arrisquemos. Isso não é uma adesão dogmática ao conjunto de conceitos lançados no mundo por esse pensador, nem tampouco uma paixão pela vida que permitiu a eclosão da obra. É mais uma pergunta pelo fantasma que Derrida mesmo é e que, assim sendo, que faz jus ao respeito à herança espectral que ele mesmo defendeu.

1 Disponível em https://territoriosdefilosofia. wordpress.com/2014/05/04/documentariodailleurs-derrida/. Acesso em 29/10/2020.
No filme, que se pretende biográfico, Derrida desde o início diz ser impossível algo como uma autobiografia, uma vez que ela pressuporia o conhecimento de uma identidade, que tornaria possível dizer "eu". Mas esse "eu" não pode ser dado em uma presença, da qual nasceria o fantasma identitário de que fala Derrida. A busca dessa possibilidade está materializada na escrita, um garimpo de existências, ainda que fantasmagóricas: "se escrevemos autobiografias é porque somos movidos pelo desejo e pelo fantasma desse encontro com o eu que finalmente se restituiria" (DERRIDA, 1999, $\mathrm{s} / \mathrm{p}$ ). Acrescenta que se alguém encontrasse esse "eu" não escreveria mais, não demarcaria nem traçaria nada mais, não viveria mais.

Diante desse olhar que escreve com imagens, na composição cinematográfica, tenho algumas inquietações a apresentar ao Derrida redivivo: por que tanto escrever se, de saída, já não há mais que uma perseguição a uma origem e uma traço identitário, pressupostos como inexistentes ou inalcançáveis? Por que falar de si, dar-se à escrita biográfica, quando já se prevê que ela não carregará senão espectralidades? Por que constituir-se em uma permanência espectral, para sempre poder retornar e frequentar as existências de humanos à cata de sentidos, se a busca de sentidos não permite qualquer resolução? Em outros termos, haveria intenção no ato de deixar seu rosto, ao final de uma escrita-imagem biográfica, para demarcar o fantasma em que se constituiria? Por fim, haveria algo como o apagamento dos fantasmas?

Para avançar na discussão dessas inquietações, precisamos rever algumas sugestões conceituais apresentadas por Derrida: o fonocentrismo; o mal de arquivo e a espectralidade. Depois de uma sintética revisão 
desses conceitos, avançaremos para a discussão da escrita como busca identitária ou como criação de fantasmagorias, seguida da questão relativa ao interesse de Derrida por essa escrita. Por fim, voltaremos a nos colocar diante do fantasma de Derrida e responder à questão sobre a (im)possibilidade de apagamento dos espectros.

\section{Rastros, suplementos e a escrita}

Iniciemos pela análise que Derrida faz da teoria etnológica de Lévi-Strauss, na qual vê ressonâncias do problema da distinção entre fala e linguagem escrita. 0 foco dessa análise é uma perspectiva que tomaria a fala não escrita de povos ditos primitivos como uma fala comunicativa, mas que não se prestou à escrita, portadora de um sentido restrito e aprisionado nela mesma. Essa perspectiva só é possível amparada na ideia de inspiração saussuriana: a distinção entre uma linguagem pura, a fala, e uma linguagem derivada, que representa a voz presente a si. Embora Saussure tenha afirmado um sistema linguístico em que a fala e a escrita são instâncias que se imbricam, algumas interpretações do VI capítulo da Introdução do seu Curso de linguística geral, Representação da língua pela escrita, colocam em destaque um tratamento controverso baseado em sua distinção:

A língua e a escrita são dois sistemas distintos de signos; a única razão de ser do segundo é representar o primeiro [...]. 0 objeto linguístico não se define pela combinação da palavra escrita e da palavra falada; esta última por si só constitui tal objeto (SAUSSURE, 2006, p.34).

Logo na sequência dessa consideração, Saussure lembra que o aprendizado da escrita é posterior ao da fala, de forma que se atribui uma importância à escrita que ela não tem. É essa assertiva o ponto de partida da análise de Derrida: a escrita seria, para Saussure, um "fora', uma representação exterior do "pensamento-som" (DERRIDA, 2017, p.38). Esse tema central de Derrida, no texto Gramatologia, é referido com o termo "fonocentrismo" ${ }^{2}$, a redução histórico-metafísica da escrita à categoria de instrumento subordinado a uma linguagem plena e originalmente falada. No entanto, Derrida considera questionável essa redução da escrita à representação no interior de um pensamento que comportou o arbitrário do signo. Coelho (2013, p.165) destaca esse reconhecimento de Derrida concedido ao brilhantismo saussuriano, na medida em que impediu pensar o signo como "signo de", apontando para a ausência de elo causal entre significante e significado, e exigindo pensá-lo no interior de uma estrutura. É nesse sentido que especulará sobre a possibilidade de uma antevisão de Saussure sobre a inseparabilidade entre fala e escrita no sistema linguístico, sendo os argumentos expostos nos capítulos introdutórios do Curso... apenas o meio para sistematizá-la.

A esse respeito, Santos (2018, p.480) destaca a sugestão de Derrida de que "seu texto escreve o que não diz, sugere o que não afirma" e "antevê a possibilidade de uma ciência dos signos em geral, não subordinada à hierarquia da phoné/logos". Isso talvez se confirme pelas assertivas que são apresentadas no avançado da obra saussuriana,

20 termo fonocentrismo é citado no primeiro capítulo de Gramatologia. Derrida o apesenta como "proximidade absoluta da voz e do ser, da voz e do sentido do ser, da voz e da idealidade do sentido". A fala estaria relacionada com uma noção de signo que implica a distinção do significado e do significante, que "permanece, portanto, na descendência deste logocentrismo que é também um fonocentrismo: "Já se pressente, portanto, que o fonocentrismo se confunde com a determinação historial do sentido do ser em geral como presença" (DERRIDA, 2017, pp.1415). 
no capítulo IV, entre as quais, a que enfatiza que o significante linguístico, em sua essência, "não é de modo algum fônico, ele é incorpóreo, constituído não por sua substância material, mas somente pelas diferenças que separam sua imagem acústica de todas as outras" (SAUSSURE, 2006, p.138). Comentando esse ponto, Mota (1997, p.307) considera que "a tese do arbitrário do signo, segundo Derrida, é obstáculo mesmo para a distinção radical entre signo oral e signo gráfico", de maneira que Saussure nunca teria pensado a escrita como representação da língua falada, mas "precisou dessas noções 'inadequadas' para detectar a 'exterioridade' da empiria gráfica, e também sonora, relativamente aos significantes".

Não obstante, a linguagem falada, segundo Derrida (2017, p.13), estaria sendo considerada, por muitos teóricos, mais próxima de uma significação natural do que a escrita, que apenas fixaria convenções, estando associada a um caráter derivado, técnico e representativo. A escrita, diz ele, "não teria nenhum sentido constituinte", sendo a derivação "a própria origem da noção de significante", ao qual ela é associada (DERRIDA, 2017, p.14). Tudo se passa como se algo escondido na fala, um significante puro, uma "substância fônica", forjasse as diferenças entre mundano e não mundano, fora e dentro, idealidade e não idealidade, transcendental e empírico (DERRIDA, 2017, p.9).

Como se vê, a própria explicitação de um originário na fala já recai sobre o uso de oposições binárias que caracterizam o pensamento ocidental, nas quais se evidencia o conflito entre natureza e cultura que Derrida denunciará como subsumido no discurso etnográfico, ainda quando as ciências humanas pensaram tê-lo superado. Contra essa prevalência das oposições binárias, que facilmente conduz a uma dimen- são conceitual excludente das diferenças, Derrida sugere a ideia de rastro, ou grama, como uma irredutibilidade a qualquer experiência, algo que "deveríamos proibir a nós mesmos de definir no interior do sistema de oposições da metafísica" e que não poderíamos associar a uma "origem do sentido em geral” (DERRIDA, 2017, p.11). 0 termo, em francês trace, sugere as marcas deixadas por uma ação ou pela passagem de um ser ou objeto (DERRIDA, 2017, p.22). Entendamos: quando o discurso já se movimentou na lógica das oposições binárias, é porque já se assumiu o pressuposto de um sentido originário que pudesse se desdobrar em isto ou aquilo, afirmação ou negação, derivação de significados. A busca desse originário é que justifica a fé no acesso ao ser plenamente presente, fundamento do que Derrida denomina como metafísica da presença.

Em Gramatologia, Derrida (2017) defende que haveria, no modo do logocentrismo, uma crença na possibilidade de apreensão do ser do ente como essa presença. Quando Derrida fala da presença na perspectiva do arquivo, em Mal de arquivo (2001), está se referindo a essa busca de um sentido originário que poderia se dar como presença. Quer, por essa via, evitar qualquer tentativa de "restaurar ou explicitar uma ontologia", ou atingir "intuições ontológicas profundas acedendo a uma verdade originária" (DERRIDA, 2017, p.24).

A busca de um sentido originário, no interior da linguagem, resultaria sempre uma remissão interminável a significantes, o que demonstra a impossibilidade de acesso e a impertinência de discursos que se pautam na justificativa da presença totalizadora do sentido. A fala, segundo Derrida, sempre foi tomada como mais próxima dos sentidos originários que a escrita, o que identificará, sem muitos esforços, na filosofia de 
Rousseau e na etnologia de Lévi-Strauss. A escrita, no âmbito dessas filosofias, seria considerada suplemento da fala. É nesse sentido que detalha a tomada da voz como auto afecção, presença de si a si do sujeito cognoscente. A voz seria, segundo Derrida, uma produção do logos como auto afecção, pela qual o sujeito sai de si em si, sendo o emissor do significante que o afeta. Ela provoca uma suspensão do apelo a um significante exterior a si, espacial, na medida em que é a consciência da voz no ouvir-se falar. Ela sinaliza, portanto, para o originário sem mediações.

Derrida vê em Lévi-Strauss um cientista inquieto que ora apoia-se na diferença entre physis e seus outros (artes, técnica, lei, instituição, sociedade), ora conduz ao seu ponto de apagamento. A oposição entre natureza e cultura aparece nitidamente na discussão empreendida por Lévi-Strauss a respeito do incesto, a partir do registro de sua interdição no povo Nhambiquara, fato que interpreta como prova de uma condição cultural sobreposta à pura natureza. Segundo Derrida (2017, p.128), o escândalo do incesto só aparece no momento em que, "renunciando a uma 'análise real' que nunca nos proporcionará diferença entre natureza e cultura, passava-se a uma 'análise ideal' permitindo definir o duplo critério da norma e da universalidade". Tudo se passa como se toda análise já se iniciasse de uma estrutura previamente pensada, aberta pelas investidas de um método apoiado na distinção natureza-cultura.

A necessidade de transpor esse a priori foi reconhecida pelo próprio Lévi-Strauss em Pensamento selvagem (1962). Apesar disso, Derrida continua apontando em Lévi-Strauss o desdobramento do conflito natureza e cultura em uma ideia de progresso da linguagem em direção a um sentido pró- prio. Um incidente, entre os Nhambiquara, em que o etnólogo nega o caráter de escrita aos esboços feitos pelo chefe da tribo, considerando-os pura imitação, soma-se a esse traço etnocêntrico, comentado por Moraes (2013, p.149, grifos do autor): “Derrida mostra que Lévi-strauss, ao traduzir a expressão iekariukedjutu por 'fazer riscos',', estaria mais uma vez se deixando tomar pelo etnocentrismo linguístico, "abandonando deste modo toda a possibilidade de significação da expressão indígena e desconsiderando o próprio ato de escrever".

É também nesse contexto que Derrida discute a importância que o etnólogo deu ao nome próprio, como presença a si, nos estudos sobre os Nhambiquara, povo facilmente interpretável como uma infância da humanidade, no jogo das oposições próprio do discurso metafísico. Os Nhambiquara interditam o nome próprio, fenômeno linguístico atrelado ao mito metafísico da origem, produzindo uma transgressão à presença a si e à propriedade. Os nomes nada mais são que indicativos de possíveis classificações, de estados transitórios da subjetividade, não podendo ser a marca da identidade e não se aplicando à presença plena, como queria o logocentrismo e, em parte, o etnocentrismo nele apoiado. É nesse sentido que Derrida aponta:

É porque o nome próprio nunca foi possível a não ser pelo seu funcionamento numa classificação e, portanto, em um sistema de diferenças, numa escritura que retém os rastros da diferença, que o interdito foi possível, pôde jogar, e eventualmente ser transgredido, como veremos. Transgredido, isto é, restituído à obliteração e à não propriedade de origem (DERRIDA, 2017, p.135).

O problema apontado por Derrida no tratamento etnológico dos Nhambiquara se baseia na incongruência da recusa de uma 
linguagem representativa a uma sociedade capaz de obliterar o próprio (o nome próprio). A dificuldade estaria em Lévi-Strauss, que dentro da clausura metafísica, precisou convencionar com os indígenas nomes de empréstimo, pelos quais seriam designados. Da sua perspectiva, haveria uma forma de suprimir o interdito imposto por essa sociedade sem nomes, para alcançar um oculto regime de classificação, "a inscrição num sistema de diferenças linguístico-sociais" (DERRIDA, 2017, p.138). Essa intenção revelaria, segundo Derrida (2017, p.139), uma violência, na medida em que tenta desnudar a não identidade nativa, revelando por efratura o nome que se pretende próprio. De fato, o mesmo Lévi-Strauss relata, em Tristes trópicos, um conflito estabelecido a partir da estratégia persuasiva de sua ação etnográfica para revelar nomes não pronunciáveis. Derrida (2017, p.146) faz referência a esse episódio como "guerra dos nomes próprios", motivada pelo estranho etnógrafo e seu sonho de uma presença plena fechando a história e suprimindo diferenças entre sociedades e culturas.

Se nos demoramos nessa questão dos Nhambiquara é porque o questionamento de Derrida a partir da perspectiva de Lévi -Strauss nos permite apontar um possível reducionismo não evitado pelo etnógrafo: um etnocentrismo que se pensa como antietnocentrismo, na medida em que parte de um binarismo entre "povos sem escritura", detentores de uma linguagem pura, autêntica, e aqueles cuja língua não está liberta da escrita, que se desdobra na distinção dentre sociedades históricas e sem história (DERRIDA, 2017, p.150).

Há, portanto, um pressuposto oculto no pensamento de Lévi-Strauss que, ao que parece, ele mesmo quis ocultar, considerando estar em uma abordagem antietnocêntrica.
Seus indicativos: existência de algo natural e antinatural entre diferentes povos (o incesto e sua interdição); manifestação de algo mais próximo de um originário e mais derivado (a fala como linguagem pura e a escrita como significação); o testemunho de apreensão da ideia de propriedade (interdição de nome próprio e competência em classificação). Na anterioridade desses binarismos, pode-se prever o pressuposto de um originário, que seria o alvo mesmo da intencionalidade etnológica: um sinalizador de aspectos humanos que derivariam em diferentes culturas.

\section{A busca da origem}

A busca de um originário resulta em uma intenção frustrada, na medida em que tudo que se pode encontrar é uma dinâmica de diferenciações que tem a própria diferença como ponto de partida. 0 pensamento ontológico opera sempre a partir da tentativa de apagamento da diferença (différance) ${ }^{3}$, anterior a qualquer definição, não podendo suportar a produção interminável do diferir. Há um interesse envolvido nesse apagamento e na busca pelo originário que é mais que epistemológico.

Derrida inicia o primeiro capítulo de sua obra Mal de arquivo nos lembrando que a palavra "arquivo" deriva do termo Arkhê, que designa, ao mesmo tempo, começo e comando: princípio da natureza ou da história, onde as coisas começam, e princípio da lei, pela qual os homens e os deuses comandam, onde se exerce a autoridade e se implanta a

3 Para Derrida, a ideia de diferença (différance) é anterior à distinção ser-ente e à presença como materialidade objetificável. Pinto Neto (2015, p.116), comentando esse conceito derridiano, associa a diferença (différance) a uma pura virtualidade enquanto possibilidade pré-originária, um movimento diferencial ilimitado contido, provisoriamente, em uma materialidade 
ordem social (DERRIDA, 2001, p. 11). Dessa forma, o interesse pelo arquivo já prevê um exercício de poder.

Poderíamos considerar que o arquivo subtrai algo da vida, constituindo um fragmento de história que, uma vez arquivado, está sujeito ao esquecimento, à destruição. Nas conduções psíquicas descritas pela psicanálise, está previsto esse apagamento da memória. No arquivamento material, há também uma potência destrutiva, colocada em ação tanto pelo arquivista, por se utilizar do poder de fragmentar o mundo dos fatos e arquivar o fragmento numa espécie de testemunho incontestável dos fatos, assim como por quem reinterpreta o material arquivado. Em todo processo de arquivamento, mantém-se a possibilidade de supressão de virtualidades que se quer negativar, esquecer, colocar em segredo. É para esses fantasmas que Derrida aponta, querendo ampliar o que o arquivamento, necessariamente, reduziu no exercício de um mal de arquivo.

Para o mal de arquivo, Derrida mesmo apresenta uma definição: "a pulsão de morte não é um princípio. Ela ameaça de fato todo principado, todo primado arcôntico, todo desejo de arquivo. É a isto que mais tarde chamaremos de mal de arquivo" (DERRIDA, 2001, p.23). Movimenta esse mal de arquivo a aposta no princípio arcôntico que reúne a busca da origem e a consignação. Tal aposta é entendida como a coordenação em um sistema no qual todos os elementos são reunidos em uma configuração ideal (DERRIDA, 2001, p.14). A possibilidade de esquecimento ou do apagamento voluntário que perpassa a lógica do arquivamento configura seu caráter de pulsão de morte.

Para melhor explicitar a problemática do arquivamento, Derrida transita na história e na psicanálise. Pretende questionar a versão clássica do trabalho intelectual presente nos discursos da historiografia. Nessa versão, "o arquivo seria um conjunto de documentos estabelecidos como positividades, na sua materialidade, e que seria ainda, na sua pretensa objetividade, o reflexo do que ocorreu de fato na experiência histórica", representando um monumento da tradição (BIRMAN, 2008, p.109). Está no alvo das discussões derridianas justamente essa ingenuidade de não prever as influências do arquivamento, os exercícios de poder nele engendrados, os conteúdos do arquivo colocados como passados e fixos. Há uma virtualidade no arquivo não previsto nesse conceito, condição coerente com a possibilidade de tomá-lo como sujeito à destruição.

A distinção entre verdade material e verdade histórica, retomada do pensamento freudiano por Derrida, na análise do arquivo, aponta para a possibilidade de desmantelamento dessa fixidez do arquivo. A verdade histórica poderia ser aventada a cada investida interpretativa sobre o material arquivado, o que, ao mesmo tempo em que inaugura uma potência de desconstrução, repete as mesmas tramas da ação arquivística. No comentário de Birman (2008, p.116), o arquivista e o intérprete constituiriam, por suas operações de organização e leitura, a consignação do arquivo. As bases da psicanálise ampliariam, na direção dessa interpretação, os limites do arquivo:

0 arquivo não se constituiria apenas de traços patentes e ostensivos, mas também pelas múltiplas leituras possibilitadas pela condição de posterioridade do intérprete e pela ação das operações do recalque e da repressão, que transformariam o que é patente em latente e virtual (BIRMAN, 2008, p.118).

Seria preciso admitir uma virtualidade, uma espectralidade, que minimizaria a ilusão de pura objetividade do arquivo. 
Freud havia suspeitado dessa espectralidade, mas não avançou para a suspensão da busca de uma originalidade que desse significação e ordem aos arquivos na dimensão psíquica. Derrida considera que o pensamento freudiano tem o mérito de não negligenciar a espectralidade, os fantasmas e assombrações, mas, ao tentar dar conta deles de modo positivo, tentou conjurá-los. Se leva em conta os fantasmas, é para dar conta deles, explicar e reduzir a crença neles (DERRIDA, 2001, p.122).

Esse rastro denunciador da busca de uma verdade no delírio levou Freud a reafirmar a conjuração do fato ao arquivo. Foi com essa disposição que julgou acessar, a partir de uma experiência pessoal, a origem de sua própria alucinação. Freud reconheceu experimentar uma alucinação furtiva, percebendo-se diante de um fantasma: a imagem de uma paciente morta que ele pensa ver, para logo em seguida perceber que ela apenas ressurge no corpo de sua irmã viva, que o procura em seu consultório.

Nessa mesma inclinação à busca de uma origem que justifique a espectralidade, na obra $O$ delírio e os sonhos na 'Gradiva" de W. Jensen, Freud analisa o romance de Jensen, Gradiva: uma fantasia pompeiana, onde há um jogo entre a imagem e a realidade, na atmosfera alucinatória do arqueólogo Hanold. Após notar a imagem de Gradiva esculpida em alto relevo, réplica da obra do século II, em sonho, Hanold visualizara a morte de Gradiva e seu soterramento nas cinzas de Pompeia. Inaugura, motivado por essa imagem, uma busca arqueológica nas ruínas, onde se espanta com a visão de uma mulher que associa ao fantasma de Gradiva, descobrindo posteriormente se tratar de uma mulher real, Zoe, amiga de infância, por quem nutria sentimentos reprimidos. Na análise de Freud, ganha foco o fetiche de
Hanold associado à imagem, pela vinculação com a lembrança dessa figura feminina da infância, movimentada por recalques. Há, no entanto, uma verdade que permanece recalcada no delírio: "a verdade é espectral, fantasmática, eis aí sua parte de verdade irredutível à explicação". Para Derrida (2001, p.117), isso permite considerar que Freud sofreu do mal de arquivo.

Estar com mal de arquivo, não pode significar outra coisa que não sofrer de um mal, de uma perturbação ou disso que o nome "mal" poderia nomear. [...] É dirigir-se a ele com um desejo compulsivo, repetitivo e nostálgico, um desejo irreprimível de retorno à origem, [...] uma saudade de casa, uma nostalgia de retorno ao lugar mais arcaico do começo absoluto (DERRIDA, 2001, p.118).

Toda ciência comporta uma prática arquivística e Derrida nos lembra o desenvolvimento de uma tecnologia apropriada às suas materialidades: "tecno-ciência, a ciência só pode consistir, em seu próprio movimento, em uma transformação de técnicas de arquivamento, de impressão, de inscrição, de reprodução, de formalização, de codificação e de tradução de marcas" (DERRIDA, 2001, p.26). Lembremos que, nas ciências que guardam relações com práticas etnográficas, um arquivamento de materiais advindos de discursos (a fala, a voz) como fonte de dados para a interpretação dos fenômenos sociais, respeitando o que Derrida aponta como uma analogia entre o fonológico e o sociológico, também configura um fonologismo legitimador a uma ciência que se dá como modelo de todas as ciências ditas humanas (DERRIDA, 2017, p.127).

Consideremos que, também na escrita biográfica, esse arquivamento é, por vezes, o norteador de uma reconstituição histórica da existência. Aí também, a espectralidade é furtiva ao mal de arquivo, impedindo qual- 
quer síntese reducionista e contrariando a busca das origens.

\section{Os espectros}

Não se trataria, no entanto, de abandonar os fantasmas na sua inacessibilidade. Tratase, para Derrida, de uma questão de justiça. Seria preciso "falar do fantasma, até mesmo ao fantasma e com ele, uma vez que nenhuma ética, nenhuma política, revolucionária ou não, parece possível, pensável e justa, sem reconhecer em seu princípio o respeito por esses outros" (DERRIDA, 1994, p.11). Comentando sobre a responsabilidade advinda da espectralidade proposta no pensamento derridiano em Espectros de Marx, Dias (2017, p. 42) destaca: "Derrida advoga o reconhecimento dos que não estão mais no presente, senão sob a forma de espectros para uma ética possível", assim como "uma revisão das dívidas históricas e de ações de reparação dessas dívidas".

Um duplo, "nem espírito nem corpo ou espírito e corpo", é o que caracteriza o espectro, segundo Derrida (1994, p. 6). 0 espectro é um "presente não-presente, um estar-aí de um ausente ou de um desaparecido", sendo, portanto, alguma coisa que, precisamente, não se conhece, que não se sabe "se responde por um nome e corresponde a uma essência", alguma coisa que não pode ser nomeada (DERRIDA, 1994, p.21). Outra característica do espectro é ver sem ser visto, não estando suscetível à nossa mirada. De acordo com Paz (2017, p.2764), na espectrologia derridiana, do seu lugar impreciso, o espectro não apenas vê sem ser visto, mas se constitui numa fonte de demandas invisíveis, mas prementes, quando não inesquiváveis.

A espectralidade prevê uma "disjunção da temporalidade, cujos recortes temporais e espaciais se fundem entre as heranças e dívidas históricas e o presente vivo", suscitando uma "crítica radical aos limites dicotômicos e totalizantes, desestabilizando reducionismos, essencialismos e conceitos rígidos" (DIAS, 2017, p.43). 0 espectro é justamente aquilo que não se deixa dizer por meio de uma metafísica da presença.

O termo "espectros", em Derrida, está ligado à ideia de hantologie, ou espectralogia, que se opõe à ontologia binária do ser, uma das grandes faces do pensamento derridiano. Em Espectros de Marx, a proposta é ir além da ontologia, pensando aquilo que nunca se faz inteiramente presente, mas na forma de rastro. A imagem dessubstancializada é, então, a do espectro. A indecidibilidade derridiana (nem isto, nem aquilo), visa eliminar de vez os binômios metafísicos, e por isso a fantasmologia, que opera nas inconsistências do real, se opõe à ontologia (DIAS, 2017, p.46).

De acordo com Pinto Neto (2015, p.18), Espectros de Marx é a obra em que Derrida utiliza de forma mais frequente a expressão hantologie (espectrologia), visando superar a ontologia que afirma o primado do ser e o dualismo ôntico/ontológico. $\mathrm{Na}$ busca de uma dimensão dessubstancializada, de uma inconsistência ontológica, a imagem recorrente passa a ser a do espectro, apontando para uma "virtualidade como condição de toda atualização", em uma lógica que supera o substancialismo do materialismo marxista, abrindo espaço para um materialismo imaterial (PINTO NETO, 2015, p.119-120), um "modelo de materialismo energético com forças sem presença" (PINTO NETO, 2015, p.124).

A espectralidade que, portanto, escapa a qualquer síntese intelectual, à ideia da pura presença e ao mal de arquivo, encontra, na escrita, amplos espaços. 0 texto anuncia, o tempo todo, a possibilidade da morte, do autoextermínio, sem negar ser abrigo dos 
rastros e das fantasmagorias que sempre sobrevivem. É nesse sentido que o tema dos fantasmas nos permite revisitar o pensamento sobre a escrita com a suspeita de que o jogo de remessas significantes, que todo texto encena, é movimentado pelo encontro com espectros.

0 trajeto feito até aqui, originado pela preocupação em esboçar alguns elementos centrais da filosofia de Derrida que nos permitissem chegar à noção de espectralidade, nos abre, agora, a possibilidade de pensarmos sobre os impulsos da escrita, com imagens ou palavras, na literatura e no cinema, como gestação e dispersão de fantasmas, entre eles, o do próprio Derrida.

\section{Palavras, imagens e espectralidades}

Palavras e imagens são equiparáveis, em Derrida, a partir de seus traços de espectralidade. As palavras podem, mesmo, desenhar imagens.

Pimentel considera que "o texto derridiano é de uma profusão de reflexos, de pinturas distendidas em palavras-imagens, desenhos que se assemelham a seus próprios desenhos de escrita, fotografias que recontam o negativo de sua escrita de imagem" (PIMENTEL, 2015, p.184).

A aproximação que a palavra e a imagem guardam com a dimensão da espectralidade justifica a proximidade com que Derrida as trata, associando o trabalho de montagem cinematográfica ao da escrita. Há algo que torna as coisas visíveis, a partir delas, palavra e imagens, mas que não é da ordem do visível, compartilhamento que desestabiliza a classificação das artes entre discursivas e visuais. Bernardo assim sintetiza essa ideia:

Não há arte não espacial, advoga Derrida, ou que não plasme um efeito de espaçamento: as artes não discursivas portam sempre discursividade, do mesmo modo que as artes discursivas portam sempre não-verbalidade: toda a arte, incluindo a arquitectónica, a escultórica e a pictórica, por natureza mais rebeldes à palavra e mais muradas no silêncio, está repleta de discursos virtuais (BERNARDO, 2017, p.62).

Derrida admite a invisibilidade em toda imagem. As artes nos sugerem o invisível. Há um suporte de invisibilidade em todo visível, defende Derrida em Pensar em não ver. Reforça: se não é visível o que torna a coisa visível, "então uma certa noite vem cavar um abismo na própria apresentação do visível" (DERRIDA, 2012, p.399). É com esse traço de invisibilidade que o artista cria. Seu fazer pressupõe o que Derrida chama de um enceguecimento. Há um momento em que o artista que desenha está cego, quando é surpreendido pelo próprio traço, uma "cegueira que aflora os demais sentidos", "que deixa por instantes os conceitos ou pré-conceitos que formulam o mundo visível para se entregar ao abismo de uma certa noite" (PIMENTEL, 2015, p.183).

É assim que o desenhista dá a ver o que não vê. Ainda quando o desenho é representativo, o traço escapa ao campo de visão (DERRIDA, 2010, p.52). Memórias de cego: o auto-retrato e outras ruínas é título de uma exposição feita no Louvre, em 1990-1991, sob curadoria de Jacques Derrida, em que inclui desenhos relacionados ao tema da cegueira. Freire destaca do texto derridiano que a acompanha: "haveria em todo ponto de vista (point de vue) uma espécie de vista nenhuma (point de vue), um invisível constituinte de toda visão" (DERRIDA apud FREIRE, 2012, p.187, grifos da autora).

Uma escrita sem o apoio da visão seria como um desenho de cego: quando se escreve sem ver, diz Derrida (2010, p.11), 
"uma mão de cego aventura-se solitária ou dissociada, num espaço mal delimitado" tateando e inventando um traço que "não se regula pelo que é presentemente visível" (DERRIDA, 2010, p.51). Mallet (2002, p.3637), na obra La musique em respect, cita o texto Memórias de cego..., destacando a consideração que Derrida faz lembrando Van Gogh: o artista vai de uma cegueira a outra, cego para qualquer modelo, de forma que "desenhar é a ação de se abrir uma passagem para atravessar uma parede invisível" e fazer o autorretrato é fazer o retrato de um homem cego, tendo seu rosto "afundado na noite". Comentando esse ponto cego, Freire (2012, p.192) considera que "a impossibilidade da visão se apresenta como a própria possibilidade da escrita, do traço, do registro".

Bernardo, discutindo a relação de Derrida com o cinema, destaca que o pensamento do cinema é um pensamento da espectralidade, que sugere essa proximidade entre "a cena da escrita e a técnica da rodagem, da montagem e da imagem cinematográficas" (BERNARD0, 2017, p.53).

No cinema, Derrida verá a possibilidade da permanência da virtualidade dos espectros para além da finitude do espectador, sendo que ela se positiva no tempo para além da sua morte: "tal imagem poderá ser reproduzida na nossa ausência, como já o sabemos, estamos já assediados por este porvir que porta a nossa morte. A nossa desaparição já está ali" (DERRIDA apud BERNARDO, 2017, p.89).

Freire (2014, p.64) também nos lembra que "a fenomenologia espectral do cinema, tal como abordada pela desconstrução, mostraria um certo 'não-ver' na base de toda visão, isto é, uma certa cegueira em todo ponto de vista". Isso confronta, de fato, o questionável pensamento ocidental foca- do na apreensão visual como possibilidade de acesso à verdade dada na presença plena de sentido.

Os espectros, no entanto, não estão apenas nas imagens associadas aos fantásticos, nos filmes com vampiros e espíritos. Derrida aponta para uma espectralidade que não se reduz a isso, expansível do começo ao fim da imagem cinematográfica. Comentando essa experiência, Ribeiro (2014, s/p) considera que, para Derrida, todo filme é um filme de fantasmas, sendo a imagem cinematográfica portadora de uma "estrutura espectral" que possibilita ao espectador a experiência de algo "estranhamente familiar".

Ao discutir o tema da espectralidade derridiana no cinema, Fernanda Bernardo destaca a assertiva de Derrida em Spectrographies: ser assediado por um fantasma "é ter a memória do que nunca se viveu no presente, ter a memória do que, no fundo, nunca teve a forma da presença. 0 cinema é uma 'fantomachie'. Deixai os fantasmas regressar" (DERRIDA apud BERNARDO, 2017, p.55)

Importante lembrarmos, ainda, com esses comentadores de Derrida, as produções cinematográficas Ghost Dance (McMULLEN et al,1 983) ${ }^{4}$ e Dailleur's, Derrida (FATHY, 1999) ${ }^{5}$. Destacamos, o primeiro, em que Derrida atua juntamente com Pascale Ogier, onde há uma cena ${ }^{6}$ que ele mesmo destaca em que pergunta a ela se acreditava em fantasmas, a que ela responde: "sim, agora eu acredito". Bernardo comenta que essa cena será revivida por Derrida quando de uma exposição que é convidado a fazer algum tempo depois da gravação do filme, quan-

4 Disponível em: https://www.youtube.com/watch?v=SwkjAuN-_-k . Acesso em 12/09/2020.

5 Disponível em: https://www.youtube.com/watch?v=JMQDUrQ6ctM . Acesso em 19/09/2020.

6 Disponível em: https://www.youtube.com/watch?v=0nmu3uwqzbI. Acesso em 19/09/2020. 
do a parceira já está morta. Nessa ocasião, ele reflete sobre a sobrevivência da virtualidade do filme à morte, dela e futuramente dele, e sobre como o fantasma da própria Ogier se evidenciou quando reviveu a cena: "pude então experimentar o sentimento perturbante do retorno do seu espectro, o espectro do seu espectro reaparecendo para me dizer, reaparecendo-me a mim aqui agora: 'Agora... agora... agora, sim, acredita em mim, eu acredito em fantasmas'” (DERRIDA apud BERNARDO, 2017, p.87).

É nesse sentido que Freire sintetiza a fantasmagoria que a imagem cinematográfica inevitavelmente lança no mundo: "o filme, pode sobreviver a suas mortes e mesmo se os dois ainda estivessem vivos, estariam já a partir dali, transformados em fantasmas (FREIRE, 2014, p.63). 0 que fica, na imagem, é algo como um simulacro de vida, um resto que permanece, um fantasma. Se palavras e imagens comungam espectralidades, o que fica da escrita seria também esse resto, essa fantasmagoria.

Retomo, a este ponto, o olhar de Derrida na tela de Dailleur's, Derrida. Tudo parece se passar como se previsse, naquele instante, a sobrevida do filme à própria morte e à morte dos espectadores. Saberia que de uma existência escriturística restariam fantasmas que frequentariam espaços, acadêmicos ou não, alastrando-se em múltiplas reescritas? Se não uma clara intencionalidade, poderíamos supor um reconhecimento do inevitável alcance desses espectros do autor que é, que escreve incansavelmente, inclusive em tom autobiográfico, e de suas buscas por algo como um "eu" que permanecerá sendo? Ou a escrita não carrega qualquer intencionalidade. Ou o apego de Derrida à escrita tem a ver com uma imagem-palavra, ainda que fantasmagórica, que ele não quer ver borrada pelos riscos da fala. Não seria, por fim, a matéria espectral através da qual pretendia retornar depois de sua morte?

No momento em que me movo por essas inquietações, me recordo da tela $A$ noite estrelada (1889) de Vincent Van Gogh. Na apresentação da tela no Museu de Arte Moderna, lemos que há, nela, um campo de energia turbulenta, de onde se destaca um cipreste conectando a terra e o céu, uma árvore tradicionalmente associada a cemitérios e luto. No site do mesmo museu, há uma série de vídeos de teor quase investigativo que especulam as invisibilidades das telas e da vida de Van Gogh que, um ano depois da criação de $A$ noite estrelada, suicidou-se. Há, ao que parece, traços de espectralidade que, como no caso da experiência derridiana em Ghost Dance, se duplicam nos fantasmas sugeridos pela noite, ainda que iluminada pelas estrelas, e no do próprio artista que já não mais testemunha essa permanência que sua obra inaugurou no mundo.

No vídeo ${ }^{7}$, enquanto o narrador descreve e especula sobre a vida e a obra de Van Gogh, sua voz é embebida em uma atmosfera musical, ela mesma, tomada pela noite e por suas fantasmagorias. Logo no início, após informar os elementos que compõem a imagem da tela aqui referida, o narrador menciona o fato da tela ter sido pintada em um hospício, no ano que antecede a morte do seu autor, quando a imagem do quadro é substituída, na película, pela imagem do artista, meio que espectral, com foco no seu olhar inquisidor e, ao que parece, melancólico. Para além dessa aproximação tateante do olhar para a tela, já pressentimos toda sua marca espectral.

Essas palavras-imagens que tecem fragmentos biográficos de Derrida e Van Gogh

7 Disponível em: https://artsandculture.google. com/asset/la-nuit-transfigur\%C3\%A9e/bgEuwDxel93-Pg?childAssetId=zQFQE2liz3GQ0w\&hl $=$ pt-BR 
se recusam a entregar tudo de uma vez por todas. São silenciadas pelos olhares que já insinuam: não sobreviverei, daqui logo mais, senão como um espectro.

\section{A escrita e demarcação de rastros}

Em 1994, Derrida concedeu uma entrevista a Betty Milan, de Paris para a Folha, em que, por vários momentos, interrompeu a fala, alegando não conseguir explanar a contento as questões que lhe eram destinadas. Momento marcado, obviamente, por algum constrangimento e muita dissonância. Não obstante, em uma das suas respostas, falou de Marx, do espectro de Marx. Esclareceu que a obra Espectros de Marx não sugeria uma apologia ao retorno das análises marxistas aos nossos tempos, mas o que ficou dela como rastro, atemporal. Fantasmas não morrem nunca. 0 que não foi dito sobre o pensamento marxista, o que restou de uma apropriação redutora é o que permanece como um ruído ao fundo dos discursos teóricos e políticos.

É nesse sentido que afirma não se tratar de um retorno a Marx, mas de Marx: "questionar com o espírito de Marx não quer dizer reaplicar dogmaticamente a doutrina de Marx, voltar a uma ortodoxia marxista". 0 retorno a Marx seria como que uma redução de seus pensamentos àquilo que já fora configurado como doutrina marxista, o que, de alguma forma, significaria, segundo Derrida, "uma maneira de neutralizar Marx, de fazer dele um personagem da Academia Filosófica", de forma que sua leitura do espectro marxista pretendia protestar contra "uma certa desapropriação filosófica de Marx" (DERRIDA apud MILAN, 1994, s/p).

Nessa sua mesma lógica, será preciso que Derrida retorne sem ser reduzido a um personagem da Academia Filosófica, evitando, assim, qualquer redução dos efeitos de suas provocações, em uma tentativa de conduzi-las a um corpo de conceitos que só pudesse ser lido em consonância com algum efeito pragmático. Se não é esse personagem que se confunde com uma prática da referencialidade, é talvez a imprecisão da espectralidade que deve permear um texto onde há uma espécie de correspondência de anseios e pressentimentos, tecido em qualquer escrita não arquivística. 0 espectro, em Derrida, é isso que escapa à redução da síntese teórica e do arquivamento. Voltar aos espectros pressupõe reconhecer esse escape e manter uma "vigilância em relação a certas maneiras que os homens têm na sociedade de esquecer, dissimular" (DERRIDA apud MILAN, 1994, s/p).

Segue-se uma entrevista em tom errático e parece imperar uma pressão incontornável sentida pelo entrevistado. As questões estão escritas nos papéis nas mãos do filósofo, que as lê, por mais de uma vez, e declara não ser possível ou viável respondê-las. Uma frase parece resumir seus anseios de que aquilo tivesse um fim repentino: "eu escrevo tão melhor do que falo...".

Não parece estranho uma frase que, ao mesmo tempo em que aponta para o desejo de evitar a fala prolixa, reforça o interesse pela restituição da legitimidade da linguagem escrita, minimizada pela prevalência da fala. Em Gramatologia, como vimos, Derrida cita o fonocentrismo, apontando para a necessidade de contornar um caráter instrumental associado à escrita, distanciada do originário e da totalização de sentidos na fala.

Fala e escrita, visão e audição, dia e noite são oposições binárias que aparecem amplamente problematizadas nas obras derridianas. Estão conectadas, sendo os primeiros termos - fala, visão e dia - associados à proximidade do sentido, portanto, à síntese 
intelectual, à presença. Escrita, audição e noite são, por sua vez, colocadas longe da totalidade de sentidos, em uma dimensão de inacessibilidade que desafia as intenções logocêntricas.

Mas, não seria também a escrita, em especial a biográfica, uma forma de contenção da espectralidade? Escrever não seria, sempre, demarcar um traço identitário que poderia não escapar à busca de elucidações e à síntese intelectual? A escrita não seria, além de rastro, uma materialidade onde se pudesse reduzir os espectros, apagar os fantasmas? Trata-se de pensar se não teríamos na escrita de Derrida, tão minuciosamente detalhada, o suficiente para tentarmos conduzi-lo a uma presença ou se, de fato, suas palavras-imagens dadas à visibilidade guardam uma invisibilidade que não pode ser esgotada. A escrita poderia, na primeira via, trair os espectros?

\section{Trair a espectralidade?}

Me pergunto, enquanto penso no fantasma de Derrida, na possibilidade de apagamento de fantasmas. Em outros termos, nisso em que previu o que escapa à destruição, à pulsão da morte no arquivamento, haver uma força de apagamento, auto extermínio? Ao que parece, todas as imagens-palavras que, em Dailleur's..., encaminham para o olhar de Derrida, de onde partimos, desenham negações como resposta.

Insistamos: importa perguntar se seria possível traçar uma rota de busca identitária, que toda a biografia prevê e que a justificativa, como nos lembrou Derrida em Dailleur's.., procedendo o apagamento de todos os rastros. Em outros termos, a escrita poderia trair a espectralidade?

Retomemos, partindo das questões iniciais, a escrita de um espectro que parece se estender por toda a parte... Estamos diante do olhar de Derrida, já nos momentos finais do texto cinematográfico, cujo teor é biográfico, um olhar que nos frequenta com a força de um espectro. Me pergunto se, nesse momento, em que parece ver para além da câmera, prevendo alguma finitude, reconhece ter-se lançado na aventura biográfica para, simplesmente, gestar seu próprio fantasma, deixar o rastro pela tessitura da imagem e das palavras, ou para empreender a busca por um fantasma identitário.

Não há como evitar inquietações: por que tanto escrever se, de saída, já não há mais que uma perseguição a uma origem e um traço identitário pressuposto como inexistentes ou inalcançáveis? Gostaria de saber se Derrida pôde escapar, com sua escrita, a essa interminável busca de um fantasma identitário que considerava, de saída, inacessível. Nesse sentido, quando Derrida questionou a busca de origem no arquivamento, negou a possibilidade de colocar qualquer ser na luz da presença, ousou dizer, no início de um documentário sobre a própria vida e obra, que todo texto de tom autobiográfico insinua essa busca pelo fantasma identitário, não intencionava dar sua existência a uma profusão de fantasmagorias que sobrevivessem à própria morte? Em sendo assim, o desejo do fantasma e de reconhecer, inclusive na própria existência, uma artesania de espetralidades, não seria também uma intenção de contorno de uma existência sem sentido e de uma incontornável finitude? Em síntese, a pressuposição do fantasma não carregaria o indício de um desejo de ir além, de sobreviver à própria morte? Talvez sim, mas talvez tornarse uma profusão de espectros jamais tenha sido uma intenção de Marx, e tampouco de Derrida.

Já no início de Dailleur's.., a possibilidade de toda escrita é apresentada: a busca 
interminável por um eu. Defende Derrida que quem diz poder encontrar algo como esse "eu", já não escreve mais, ou melhor, já não vive mais. Logo, na sequência, Derrida está diante de um grande aquário e comenta a impaciência dos peixes, enquanto a câmera se desdobra entre o olhar de uma dessas criaturas e o do seu observador. Diz se sentir também aprisionado, diante de uma mirada e, ambos, o humano que é e o não humano, fazem a experiência do tempo, de formas absolutamente distintas. Assim começa a aparição da espectralidade de Derrida: partindo do compartilhamento com os animais não humanos, passando pelas marcas do pós-colonialismo e pela violência da tentativa de revelação do secreto, própria dos totalitarismos que forçam a identificação, avançando para a alegoria da circuncisão, que denuncia inscrições, como as que ficam no corpo, chega ao esconderijo do sublime arquitetado na escrita. Toda escrita, reforça Derrida, é uma forma de resistência e suas forças resguardam a possibilidade da transgressão.

Nesse momento, em que já enfrenta a necessidade do escape das revelações e identificações, se encaminha para a impossibilidade de escrever um livro sobre as marcas da circuncisão, que deveria tocar as raízes do inconsciente, jamais dadas à plena luz. Insistir no intento poderia significar sofrer de um mal de arquivo. Dessa perspectiva, seria impossível também apagar os fantasmas, ainda que fossem ocultados, ignorados e esquecidos. Obliterar não é, necessariamente, destruir. A escrita tomada por obscuridades, ainda quando é a escrita de si, sempre carregará um indeterminado, não revelado, não identificado, de forma que escrever à busca de uma identidade é um movimento que retroalimenta expectativas, oferecendo, a cada nova intenção, um campo de espec- tralidades. Por fim, haveria possibilidade de apagamento dos fantasmas? Para Derrida, os fantasmas persistem e, ainda que se tente livrar deles, estão sempre a retornar.

Síntese das questões dirigidas a Derrida: por que falar de si, dar-se à escrita biográfica, quando já se prevê que ela não carregará senão espectralidades? 0 jogo da escrita, entre a busca de identidade e a insinuação de espectros, parece mais um efeito radicalizador da intenção de povoar a escrita com invisibilidades que propriamente de conjurar os fantasmas. Em outros termos, a escrita se constituiria em uma forma de acenar com a própria existência a busca inglória e interminável de determinações do ser que esbarra sempre no invisível, não dito, não totalizável, mas que, nem por isso, pode abster-se de deixar marcas, olhares nas telas que vão inquirir o espectador: "você acredita em fantasmas?".

No encadeamento das imagens-palavras em Dailleur's.., Derrida confessa ter escrito muito e ele mesmo se faz a pergunta: por que se escreve tanto? Segue considerando que é inevitável se revelar na escrita e que deve, por isso, pedir perdão, já que não consegue se defender de uma espécie de pudor de dizer.

Por que escreves? Parece que você acha que o que escreve é interessante, [...] o que, de uma certa maneira, é absolutamente obsceno. 0 ato de escrever é injustificável desse ponto de vista. Então, pede perdão, como alguém que se desnuda e diz "aqui estou, olhem" e, naturalmente, pede de imediato perdão: "perdoem-me por me fazer de interessante" (DERRIDA, 1999, s/p).

Há também outro motivo para pedir desculpas, segundo ele, algo que o inquieta sempre, que tem a ver com a marca, a impressão deixada, e com a linguagem: "quando deixo uma impressão, apago a singulari- 
dade dos destinatários". A escrita poderia ferir a identidade do destinatário, sendo, assim, uma traição, um perjúrio. Ainda assim, seria preciso reconhecer que, sem qualquer marca, impressão, experiência de traição ou violência, nenhuma existência poderia se movimentar ou se escrever.

Por que, então, constituir-se em uma permanência, para sempre poder retornar e frequentar as existências de humanos à cata de sentidos, se a busca de sentidos não permite qualquer resolução? Por que, em outros termos, Derrida deixou seu rosto, ao final de uma escrita biográfica, para demarcar o fantasma em que se constituiria? Talvez porque reconhecesse a importância dos fantasmas que frequentaram sua própria existência, sem o que nenhum pulso de vida seria possível: do fantasma da perseguição política, mas também de Ogier escutando-o por horas e dando vida às invisibilidades que havia pensado - "sim, eu acredito em fantasmas" -, de Marx, de Levinas, do animal - que logo é - e que tanto marcou seu pensamento sobre a descentralização do humano. Ou talvez porque precisasse mesmo se dar como provocação para além da própria morte, havendo nisso alguma intenção, autocentrada ou não.

Garantir espaço à espectralidade é alimentar as possiblidades de constituição histórica. Interessante destacar, nesse ponto, duas imagens que aparecem no filme: as sepulturas de seus gatos e as ruínas que foram cenário da morte violenta de uma mulher, materialidades frequentadas por fantasmas. Diante das referidas ruínas, discorre sobre a trama de vozes, em que uma voz habita a outra (plurivocidade) e a violenta tentativa de apagamento de uma voz ou de redução das vozes a uma só voz (monologia). A redução dessa trama revelaria a estratégica tentativa de conjuração dos fantasmas: “a multiplicidade de vozes é também o espaço aberto aos fantasmas, aos 'retornates', ao retorno do que está reprimido, o que está excluído" (DERRIDA, 1999, s/p). Apagar vozes é, portanto, uma tirânica tentativa de ocultar, conter, silenciar os espectros de todas as vítimas de repressão. Essa ideia conduz a espectralidade a uma questão política e Derrida a explicita convocando os humanos a uma espécie de autoanálise e à responsabilidade. Nesse sentido, escrever seria uma forma de ouvir ou dar à escuta a multiplicidade de vozes, transgredindo a ocultação da espectralidade.

Resta, então, perguntar se há fantasmas sem traços humanos. Para alguém que quis enxergar os viventes para além da fronteira entre humano e não humano, da oposição entre bestialidade e soberania, seria prudente perguntar se reconhecer ao humano uma fantasmagoria não preveria, evitando qualquer especismo, pressupor os espectros dos viventes não humanos? Não o fazer não significaria, mais uma vez, assumir os sinais de um antropocentrismo fragilizado pelas próprias reflexões derridianas? $\mathrm{Ou}$ diríamos que, como há fantasmas de Marx, há também os de todos os viventes que, em alguma condição espaço-temporal, estiveram sujeitos a alguma forma de contenção, justificada nessa mesma lógica antropocêntrica? Há, por exemplo, espectros das florestas que, a essa altura, gritam errantes, como suas fuligens por aí, e que voltarão a nos frequentar sempre que pressentirmos nossa íntima conexão com tudo que é vivo?

Em síntese, trata-se de nos perguntarmos se Derrida nos deu espectros como expansão de uma humanidade, somando mais uma ilusão a tantas já materializadas em narrativas autorreferentes, ou uma escrita onde os fantasmas, sem nomes, sem feições definidas, sem propriedades necessaria- 
mente humanas, podem ser pressentidos, diminuindo assim qualquer grandiloquência na forma como constituímos imagens de nós mesmos.

A imagem que Derrida tece de si mesmo parece já se confundir com seus próprios espectros ao final de Dailleur's..., quando enfrenta a constatação da própria morte por vir. Revela-se como um fantasma que deseja reviver: "meu desejo mais forte seria recomeçar, reviver tudo, o mau e o bom, [...] o sofrimento e a possibilidade de sublimação". Não desejaria inventar coisas novas, mas recomeçar as mesmas coisas, desejo que se reforçaria na hora da morte: "o que é trágico na existência, e não só na morte, é que a significação do que vivemos, e que quando a vida é longa implica muitas coisas, determina-se mais no último momento, no momento da morte" (DERRIDA, 1999, s/p). Ao que parece, desejaria poder continuar vivendo com os próprios espectros: afirmação da vida que prevê a morte e a continuidade do que a partir dela permanece, não como uma identidade incapaz de desgarrar-se de um si mesmo, mas de uma espectralidade que se dissemina. É assim que Derrida termina sua escrita, depois de ter-se aventurado a mostrar-se, pedir perdão e, inevitavelmente, continuar: confessa que não teve notícia na história da humanidade de alguém que tenha sido mais feliz que ele e que, "bêbado de um prazer ininterrupto", permaneceu "como o contraexemplo de si mesmo, constantemente triste, privado, destituído, decepcionado, impaciente, desesperado...". Evitando o caminho da exclusão de qualquer dessas certezas, arrisca a afirmação: "Eu assino!" (DERRIDA, 1999, s/p). Uma escrita que se assina, com cada rabisco, cada marca de seus fantasmas.

Reencontro Derrida e me sinto inclinada a pensar que ele acena, com um olhar ou com palavras-imagens cheios de silêncio, apontando não para si mesmo, mas para um campo de indeterminações onde quer lançar à deriva seus espectadores-leitores. Pergunta: "vocês acreditam em fantasmas? Eles veem sem serem vistos... Não me olhem... É para lá que devem voltar-se porque toda invisibilidade guarda uma possível visibilidade.... E, perdido em suas próprias pressupostas dificuldades com a fala, escreve em um ato imagético: "Nós morremos... Eles nunca morrem".

\section{Referências}

BERNARDO, F. Derrida e o cinema. Revista Filosófica de Coimbra, n. 51, pp. 51-90, 2017.

BIRMAN, J. Arquivo e mal de arquivo: uma leitura de Derrida sobre Freud. Natureza Humana, v.10, n.1, p. 105-128, jan-jun, 2008.

COELHO, C. C. Gramatologia e Semiologia: o pensamento de Jacques Derrida diante da linguística de Ferdinand de Saussure. Sapere Aude, v.4, n.7, p.151-169, 1ํㅗ sem. 2013.

DERRIDA, J. Espectros de Marx: o estado da dívida, o trabalho do luto e a nova Internacional. Trad. Anamaria Skinner. Rio de Janeiro: RelumeDumará, 1994.

Documentário. In: FATHY, S. D’ailleurs Derrida (Documentaire). DVD (151 min). Paris: Gloria Films/Arte, 1999.

Mal de arquivo: uma impressão freudiana. Trad. Claudia M. Rego, Rio de Janeiro: Relume-Dumará, 2001.

Memórias de Cego: 0 auto-retrato e outras ruínas. Tradução: Fernanda Bernardo. Lisboa: Fundação Calouste Gulbenkian, 2010.

Pensar em não ver - escritos sobre as artes do visível (1979-2004). Org. Ginette Michaud; Joana Masó; Javier Bassas. Trad. Marcelo Jacques de Moraes. Florianópolis: UFSC, 2012.

Gramatologia. Trad. Miriam Chnaiderman e Renato Janine. São Paulo: Perspectiva, 2017.

DIAS, F. L. Espectros de Derrida na ficção bra- 
sileira contemporânea: 1964 e seus fantasmas consistentes nas obras $A$ resistência, de Julián Fuks, e Lavoura arcaica, de Raduan Nassar. Cadernos literários, n.2, v.1, p. 41-51, 2017.

FATHY, S. D'ailleurs Derrida (Documentaire). DVD (151 min). Paris: Gloria Films/Arte, 1999. Disponível em: https://www.youtube.com/watch?v=JMQDUrQ6ctM . Acesso em 19/09/2020.

FREIRE, M. C. Por amor ao traço: uma leitura de "Memórias de cego". Revista Ítaca, v.19, pp.186194, 2012.

"O retorno dos fantasmas: arriscar um pensamento desconstrutivo do cinema". In Atas do III Encontro Anual da AIM, editado por Paulo Cunha e Sérgio Dias Branco, 58-65. Coimbra: AIM, 2014.

MALLET, Marie-Louise. La musique en respect. Paris: Galilée, 2002.

McMULLEN, K.; MELLINGER, L.; OGIER, P. Ghost dance. 1983. Disponível em: https://www.youtube.com/watch?v=JMQDUrQ6ctM. Acesso em 12/09/2020.

MILAN, B. Derrida caça os fantasmas de Marx. Entrevista: Especial para a Folha, de Paris. São Paulo: Folha de São Paulo, 26 de junho de 1994.

MORAES, M. A crítica de Derrida ao etnocentrismo não declarado de Lévi-Strauss. Ensaios Filosóficos, v.VII, pp. 137-155, Abr. 2013.

MOTA, S.B.V. A Gramatologia, uma ruptura nos estudos sobre a escrita. Delta, v.13, n.2, pp. 291313, Aug.1997.

PAZ, R. G. Pensar as demandas: implicações ético-estéticas da espectrologia de Jacques Derrida nas teorias da narrativa. In: Anais da XV Abralic - Experiências literárias, textualidades contemporâneas, pp.2763-2774. Rio de Janeiro: UERJ, 2017.

PIMENTEL, D. A. Resenha de pensar em não ver. Alea, Rio de Janeiro, vol.17/1, p. 181-186, janjun 2015.

PINTO Neto, M. A estranha instituição da literatura no multiverso dos espectros. Alea, Rio de Janeiro, v.17, n.1, pp.114-126, jan-jun 2015.

RIBEIRO, M. Derrida na Cahiers du Cinéma: “O cinema e seus fantasmas". Entre Imagens, n.17, dez.2014. Disponível em https://www.incinerrante.com/textos/jacques-derrida-e-os-fantasmas-do-cinema. Acesso em 25/09/2020.

SAUSSURE, F. Curso de linguística geral. Trad. Antônio Chelini, José P. Paes e Izidoro Blikstein. 27aed., São Paulo: Cultrix, 2006.

SANTOS, A. C. Derrida e a Linguística Estrutural: uma leitura do capítulo 1 de Gramatologia. Estudos Linguísticos, v.47, n.2, p. 474-484, 2018.

Recebido em: $15 / 10 / 2020$

Aprovado em: 28/11/2020

cC) (i) Esta obra está licenciada com uma Licença Creative Commons Atribuição 4.0 Internacional. 